\title{
Clinical Features, Cancer Biology, Transplant Approach and Other Integrated Management Strategies for Wiskott-Aldrich Syndrome
}

\author{
Smitha Hosahalli Vasanna \\ Maria A Pereda \\ Jignesh Dalal
}

Department of Pediatrics, Division of Pediatric Hematology Oncology, Rainbow Babies and Children's Hospital, University Hospitals, Cleveland, OH, USA
Correspondence: Jignesh Dalal Department of Pediatrics, Division of Pediatric Hematology Oncology, Rainbow Babies and Children's Hospital, University Hospitals, I I 100 Euclid Ave, Cleveland, $\mathrm{OH}, 44 \mathrm{I} 06$, USA

$\mathrm{Tel}+\mid 2169831027$

Fax $+|216844543|$

Email jignesh.dalal@uhhospitals.org

\begin{abstract}
Wiskott-Aldrich syndrome (WAS) is a rare X-linked recessive inborn error of immunity (IEI) first described in 1937. Classic WAS is characterized by the triad of thrombocytopenia with small platelets, recurrent infections due to combined immunodeficiency, and eczema. Hematopoietic stem cell transplantation (HSCT) was the only curative option available for five decades, with excellent outcomes reported for matched sibling donors (MSD) and matched unrelated donors (MUD). More recently, alternative donor transplants such as umbilical cord blood (UCB) and haploidentical transplant have emerged as viable options due to improvements in better graft selection, cell dosing, and effective allograft manipulation measures. Gene therapy is another potential curative option with promising results, yet currently is offered only as part of a clinical trial.
\end{abstract}

Keywords: Wiskott-Aldrich syndrome, X-linked thrombocytopenia, supportive care, hematopoietic stem cell transplantation, gene therapy

Wiskott-Aldrich syndrome is a rare X-linked recessive inborn error of immunity first described in 1937. Classic WAS is characterized by the triad of thrombocytopenia with small platelets, recurrent infections due to combined immunodeficiency, and eczema. ${ }^{1,2}$ Furthermore, there is also an increased incidence of autoimmune conditions and lymphoid malignancies due to immune dysregulation. The WAS gene, which has 12 exons, is found on the short arm of the $\mathrm{X}$ chromosome at 11.22-23 locus and encodes a 502-amino-acid protein known as WAS protein (WASp). This cytosolic protein is expressed in myeloid, lymphoid, and hematopoietic stem cells (HSCs). WASp plays a key role in cytoskeletal remodeling and actin polymerization, as well as being a crucial regulator of the immunologic synapse between $\mathrm{T}$ and $\mathrm{B}$ cells. ${ }^{3,4}$ In addition, $\mathrm{T}$ regulatory function, NK cell cytotoxicity, monocyte chemotaxis, and dendritic cell shape have all been found to be aberrant in WAS patients. ${ }^{5-7}$ To date, more than 300 different WAS mutations have been discovered, with nine mutational hot spots accounting for around onethird of the overall number of mutations observed. ${ }^{8}$

The global prevalence of WAS is estimated to be 1-10 males per million. As an $\mathrm{X}$-linked disease, it usually affects males. Females are often obligate carriers; however, they can be affected by skewed lyonization, Turner syndrome, or a deleterious mutation on the paternal $\mathrm{X}$ chromosome. ${ }^{3}$ 


\section{Structure and Function of WAS Protein}

WASp has three distinct functional domains: a pleckstrin homology domain that binds phosphatidylinositol bisphosphate; a Cdc42-binding domain; and a 70-amino-acid conserved verprolin-homology domain that forms the actin-binding area and is important for actin cytoskeleton control. WASp is a downstream effector of $\mathrm{Cdc} 42$, which is a small GTPase that regulates actin polymerization and cytoskeletal structure. The interaction of WASp with the Arp 2/3 complex is required for $\mathrm{Cdc} 42$-dependent actin assembly. ${ }^{9-11}$

\section{Clinical Features}

Although classic WAS is usually diagnosed within the first few months to a few years of life, diagnosis of milder cases can be delayed much farther into adulthood. ${ }^{1,12}$ The classical triad of microthrombocytopenia, recurrent infections and eczema is seen only in about a quarter of patients.

\section{Thrombocytopenia}

Thrombocytopenia is one of the first clinical signs of WAS. It is seen in nearly $80 \%$ of the patients at the time of diagnosis and about half of them have severe thrombocytopenia (platelet count $<20,000 / \mu \mathrm{L}$ ). The bleeding manifestations might range from non-life-threatening (petechiae, purpura, hematoma, epistaxis) to severe bleeding (intestinal and intracranial). ${ }^{1,13}$ While newborns present with bloody diarrhea/bleeding from the umbilical stump or bleeding after circumcision, the most common bleeding symptoms noticed in older children include cutaneous and gastrointestinal (GI) bleeding. Bleeding-related deaths occurred in $4-10 \%$ of the patients, with serious consequences observed with GI and intracranial bleeding. ${ }^{1,12}$ Thrombocytopenia occurs regardless of the severity of the mutation, which is attributed to the instability of the mutated WASp in platelets. ${ }^{14}$ Normal mean platelet volume (MPV) is $7.2-11.7 \mathrm{fL}$ and in WAS it is usually $<5 \mathrm{fL}$. Micro platelets, considered the hallmark of WAS, were found only in $53 \%$ of the patients as reported by Sullivan et al. ${ }^{1}$ There are anecdotal reports of WAS presenting with normal or even increased MPV, particularly in the context of autoimmunity, splenectomy, and post platelet transfusion. ${ }^{15-17}$ WAS can be misdiagnosed as immune thrombocytopenia (ITP), especially when thrombocytopenia is the only presenting symptom. ${ }^{18}$
Thrombocytopenia in WAS is multifactorial and is attributed to defective platelet production from the megakaryocytes and splenic destruction involving both immune and non-immune mechanisms.

\section{Immunodeficiency}

The PID portion manifests with failure to thrive and recurrent infections due to combined immunodeficiency. The severity of immune deficiency may vary from family to family and sometimes can be life-threatening. Infections include bacterial (sinopulmonary infections, skin abscess, sepsis, meningitis), viral (herpes and severe hemorrhagic varicella), invasive fungal infections (candida), and opportunistic infections (Pneumocystis jirovecii). ${ }^{12,19} \mathrm{~T}$ cell defects are characterized by both qualitative and quantitative abnormalities. Though at birth $\mathrm{T}$ cell numbers are normal, progressive apoptosis leads to $\mathrm{T}$ lymphopenia by 6-8 years of age. Nearly half of the patients have an abnormal proliferative response to mitogens indicative of $\mathrm{T}$ cell qualitative abnormalities. B cell defects manifest with abnormal immunoglobulin profile, which includes low IgM, high IgA, and high IgE levels. IgG levels are usually normal, although the ability to mount sufficient antibody response to polysaccharide antigens and certain peptide antigens, including diphtheria, tetanus, and Hib vaccine, is decreased. This abnormal antibody response is a direct consequence of defective $\mathrm{T}$ cell and $\mathrm{B}$ cell interaction, resulting in failure of memory $\mathrm{B}$ cells to isotype switch. Abnormalities of NK cell function and phagocytic cells have also been reported. Defective NK cell cytotoxicity has been attributed to the increased risk of viral infections and malignancy. Functional defects in phagocytic cells due to defective chemotaxis, degranulation, and podosome assembly have been described, which are attributed to impaired intraphagosomal microbial killing. ${ }^{9}$ Abnormal newborn screening assays for severe combined immunodeficiency can identify a small fraction of WAS, leading to early diagnosis before the onset of clinical symptoms. $^{20}$

\section{Eczema}

Eczema roughly affects three-quarters of WAS patients, with about half of those suffering from severe refractory eczema. XLT patients have milder symptoms due to residual WASp expression. Associated food allergies and secondary bacterial infections have been associated with severe exacerbations, which tend to improve with dietary modification and antibiotics. Although the exact cause of 
eczema in WAS patients is uncertain, a skewed Th2 cytokine profile resulting in elevated $\operatorname{IgE}$ levels and ectopic dermal location of Langerhan's cell due to aberrant cell trafficking is proposed. ${ }^{9,21}$

\section{Autoimmune Manifestations}

Autoimmune manifestations were reported in $26-72 \%$ of WAS patients in various studies. ${ }^{1,4,12,22-24}$ The most common autoimmune manifestation described in WAS patients is autoimmune hemolytic anemia (AIHA). In a cohort of 55 patients, Dupuis et al found that 36\% had AIHA, 29\% had arthritis, $25 \%$ had autoimmune neutropenia, $25 \%$ had vasculitis [skin (22\%) and cerebral vasculitis (7\%)], 9\% had inflammatory bowel disease, and 3\% had renal disease. ${ }^{24}$ Other reported manifestations include autoimmune thrombocytopenia, IgA nephropathy, and a higher incidence of food and drug allergies. ${ }^{23,25}$ Autoimmunity has been described as an independent poor prognostic marker with a predisposition to malignancy. ${ }^{1}$ The mechanism of autoimmunity is correlated with impaired Treg and B cell function. Treg cells play a vital role in the prevention of autoimmunity by modulating T-effector cells, which promote autoimmunity. Treg cells in WAS patients have an impaired ability to suppress activated T-effector cells, leading to loss of self-tolerance and autoimmunity. ${ }^{2}$ Dupuis et al found a substantial correlation between high IgM levels and the development of autoimmunity. In their patient population, $90 \%$ of those with elevated IgM developed AIHA, in comparison to none with low IgM levels. ${ }^{24}$ Also, abnormal NKT cell (cells possessing properties of $\mathrm{NK}$ and T cells) function has been described to play a role in autoimmunity due to the production of autoreactive B cells. ${ }^{26}$

\section{Malignancies}

Hematolymphoid malignancies are the most common cancers associated with WAS. Adolescents and young adults are more likely to be affected than children. Sullivan et al found a $13 \%$ ( 21 of 154 patients) malignancy rate in their cohort. Hematologic malignancies were the most common, and the only three other non-hematologic malignancies reported were glioma, acoustic neuroma, and testicular carcinoma. The mean age of development of cancers in their patient cohort was 9.5 years. Due to its aggressive character, malignancy in the setting of WAS was associated with death in nearly all patients in this cohort. ${ }^{1}$ Perry et al found that the relative risk of cancer was 100 times higher in the WAS group than in the general population, and the risk increased with age. ${ }^{27}$ Lymphoid malignancies in WAS occur due to loss-of-function mutations, whereas acute myeloid leukemia (AML) and myelodysplastic syndrome (MDS) in X-linked neutropenia (XLN) occur due to gain-of-function mutations. ${ }^{28}$ NonHodgkin lymphomas (NHL), especially B cell lymphomas, have a higher incidence than Hodgkin Lymphoma (HL) in WAS patients. ${ }^{29}$ EBV-associated lymphoproliferative disorders (LPD) are frequently seen in patients receiving immunosuppressive therapy after organ transplantation but they can also occur in IEIs, including WAS. ${ }^{12,30}$

N-WASP, a protein closely related to WASp that is expressed primarily in neural cells, has $50 \%$ sequence homology to WASp and is also thought to play a role in the development of malignancies. ${ }^{33} \mathrm{~N}-\mathrm{WASp}$ is also an actin regulatory protein with a role in cytoskeletal reorganization, mainly in the actin-based filopodia in mammalian cells. N-WASp has a crucial role in cancer invasion as elucidated in various studies. This occurs through Arp 2/ 3-complex-mediated actin polymerization and matrix metalloproteinase (MMR) dependent mechanisms. Liu et al described the potential role of N-WASp as a prognostic factor in clear cell renal carcinoma. They found low expression of N-WASp correlated with poor histologic grades; however, high expression correlated with poor survival. ${ }^{31}$ Various other independent observers have described the role of N-WASp and its prognostic significance in endometrial cancer, hepatocellular carcinoma, breast cancer metastasis, and esophageal squamous cell carcinoma. $^{32-34}$

\section{Atypical Presentations}

A subset of patients with WAS rather present with atypical manifestations, and unless, already been diagnosed with WAS or there is a strong family history of WAS, this can pose diagnostic challenge. There are few published case reports of occurence of aortic aneurysms in WAS diagnosed patients during follow-up, needing immediate surgical repair. ${ }^{35,36}$ Pellier et al reported the occurrence of aortic aneurysms in 5 out of 38 patients (13\%) between the ages of $10-16$ years. ${ }^{37}$ Barutcu et al reported a 7 -yearold boy managed as chronic ITP who was diagnosed with WAS after noticing an aortic aneurysm. ${ }^{38}$ The pathophysiology of WAS-associated vasculitis remains unclear but is attributed to immunoglobulin $\mathrm{A}$ and $\mathrm{E}$ deposition in the vessel wall leading to chronic inflammation. Aneurysmal rupture is associated with a high risk of mortality, and hence some experts recommend periodic 
echocardiography and magnetic resonance imaging for surveillance due to higher likelihood of its occurrence in WAS.

He et al reported a toddler boy with WAS presenting with extensive subcutaneous bleeding, thrombocytopenia and isolated prolonged activated partial thromboplastin time (APTT). On further investigation, this patient had Factor VIII deficiency and an extremely high level of Factor VIII inhibitor, which led to the diagnosis of acquired hemophilia A. ${ }^{39}$ Patil et al described a 3-monthold male infant who presented with poor feeding/oral ulceration, coomb's positive hemolytic anemia and thrombocytopenia who was being managed as Evan's syndrome, until the development of generalized eczematous rash and the genetic testing then revealed WAS mutation. ${ }^{40}$ Severe generalized eczema when combined with bleeding manifestations and severe recurrent infections not limited to the skin should raise the suspicion for WAS as reported by Kumar et al. ${ }^{41}$

\section{Genotype-Phenotype Correlation}

Using linkage and mutation analysis it was established that XLT is caused by mutations in the same gene as WAS. WASp gene mutations result in three distinct phenotypes: Classic WAS, milder XLT variant (characterized only by thrombocytopenia/mild eczema), and X-linked neutropenia (XLN) without any findings of WAS/XLT. Jin et al found a high genotype-phenotype correlation in their research of two large cohorts in North America and Europe. ${ }^{5}$ Absent WASp expression (WASp-) leads to a more severe phenotype (WAS), whereas residual protein expression $(\mathrm{WASp}+)$ results in milder phenotypes (XLT/ XLN). ${ }^{8}$ Single nucleotide substitutions, small insertions, deletions, splice site mutations throughout the coding regions, and intron/exon junctions were the most often noted mutations in various studies. ${ }^{9,42}$ The most common mutations observed in WASp + patients were missense mutations located within the PH domain (exons 1-3), whereas WASp- patients had nonsense mutations/deletions/insertions. ${ }^{12,43,44}$ WASp activating mutations are thought to be the cause of XLN. ${ }^{28}$ Among five common mutational "hot spots", three of them $(168>\mathrm{T}$ mutation, $290 \mathrm{C}>\mathrm{N} / 291 \mathrm{G}>\mathrm{N}$ mutation, IVS6 $+5 \mathrm{~g}>\mathrm{a}$ mutation) occurred predominantly in $\mathrm{WASp}^{+}$(mild phenotype), whereas $665 \mathrm{C}>\mathrm{T}$ mutation and IVS8+1 $\mathrm{g}$ mutations occurred in WASp- patients (severe phenotype) among unrelated families $(\mathrm{P}<0.001) .^{5}$ Environmental factors and genetic determinants unrelated to WASp, on the other hand, are likely to influence the clinical phenotype, which could explain the variable WAS phenotypes seen in some families. ${ }^{1,45}$

\section{Scoring Systems}

The clinical scoring system uses five parameters, namely thrombocytopenia, the severity of eczema, infections, development of autoimmunity, and malignancy. Each component is given a score of 1 with a total score of 5 . Patients with a classic triad obtain a score of $3-4$, while those with autoimmunity or malignancy receive a score of 5 .

Any score $\geq 3$ indicates a severe phenotype, and those with a score of $<3$ indicates a milder phenotype/XLT, which is characterized by only thrombocytopenia with $\mathrm{mild} /$ no eczema, and absence/mild recurrent infections and scores anywhere between 0.5 and 2.5. ${ }^{4,19}$ A score of 0.5 is given for intermittent thrombocytopenia in the absence of other symptoms. ${ }^{46}$ This classification helps predict which patients are likely to develop severe complications and would benefit from an early HSCT. Since the disease might not have fully evolved, this scoring system is less reliable in infants and young children $(<2$ years). Hence, this predictive model is not absolute and based on the clinical course of the individual patients, further evaluation for WASp expression and/or genetic testing is needed.

\section{Diagnosis}

The management of WAS begins with a proper diagnosis of the condition as clinical manifestations are extremely heterogeneous. The classic triad is seen only in about 15$27 \%$. ${ }^{1,47}$ Because of the wide range of clinical presentations, the median age of diagnosis ranged from 1.75 to 24 months in various studies. ${ }^{19,25,48}$ Recurrent infections or autoimmunity could be the presenting complaints in a small portion of patients. WAS should always be suspected in a male patient with thrombocytopenia and low mean platelet volume. Diagnostic tests include screening for $\mathrm{T}$ and $\mathrm{B}$ cell function, mutational analysis of DNA, and flow cytometry for WASp expression.

\section{Treatment}

Depending on the severity, a variety of therapeutic options are available for patients with WAS. Potential treatment options include supportive care, splenectomy, hematopoietic stem cell transplantation (HSCT), and autologous HSC gene therapy. More than one of these modalities may be required for any one patient. WAS, being a complex and chronic disorder, is 
best managed by a multidisciplinary team including stem cell transplant physicians, pediatric immunologists, dermatologists, dietitians, geneticists, and social workers. The standard of care for classic WAS is early transplant before the onset of severe infections, autoimmunity, and malignancy. Treatment decision based on the clinical symptoms, genetic mutation, and WASp expression is described in Figure 1.

\section{Supportive Care}

Supportive care is critical in the management of patients with WAS/XLT. This includes management of bleeding symptoms, initiating antimicrobial prophylaxis and immunoglobulin (IgG) replacement for classic WAS and XLT patients with recurrent infections, and appropriate management of autoimmune manifestations and malignancy. Patients with severe eczema should be referred to dermatology and dietitian for appropriate management of food allergy. This is crucial due to increased infection risk from the central line and immunosuppression caused by the transplant. XLT requires little supportive care when compared to classical WAS. Supportive care for patients is summarized in Table 1.

\section{Alternative Therapies for Thrombocytopenia \\ Role of Splenectomy}

Splenectomy has been shown to normalize platelet counts and lower the risk of major bleeding in WAS/XLT. In one study due to normalization of platelet counts, splenectomized patients had a much longer median survival than non-splenectomized patients, with a median survival of 25 years compared to 5 years in patients who did not undergo transplant. ${ }^{49}$ However, splenectomy raises the risk of overwhelming sepsis, especially in the post-transplant period despite being on prophylactic antibiotics. Various studies

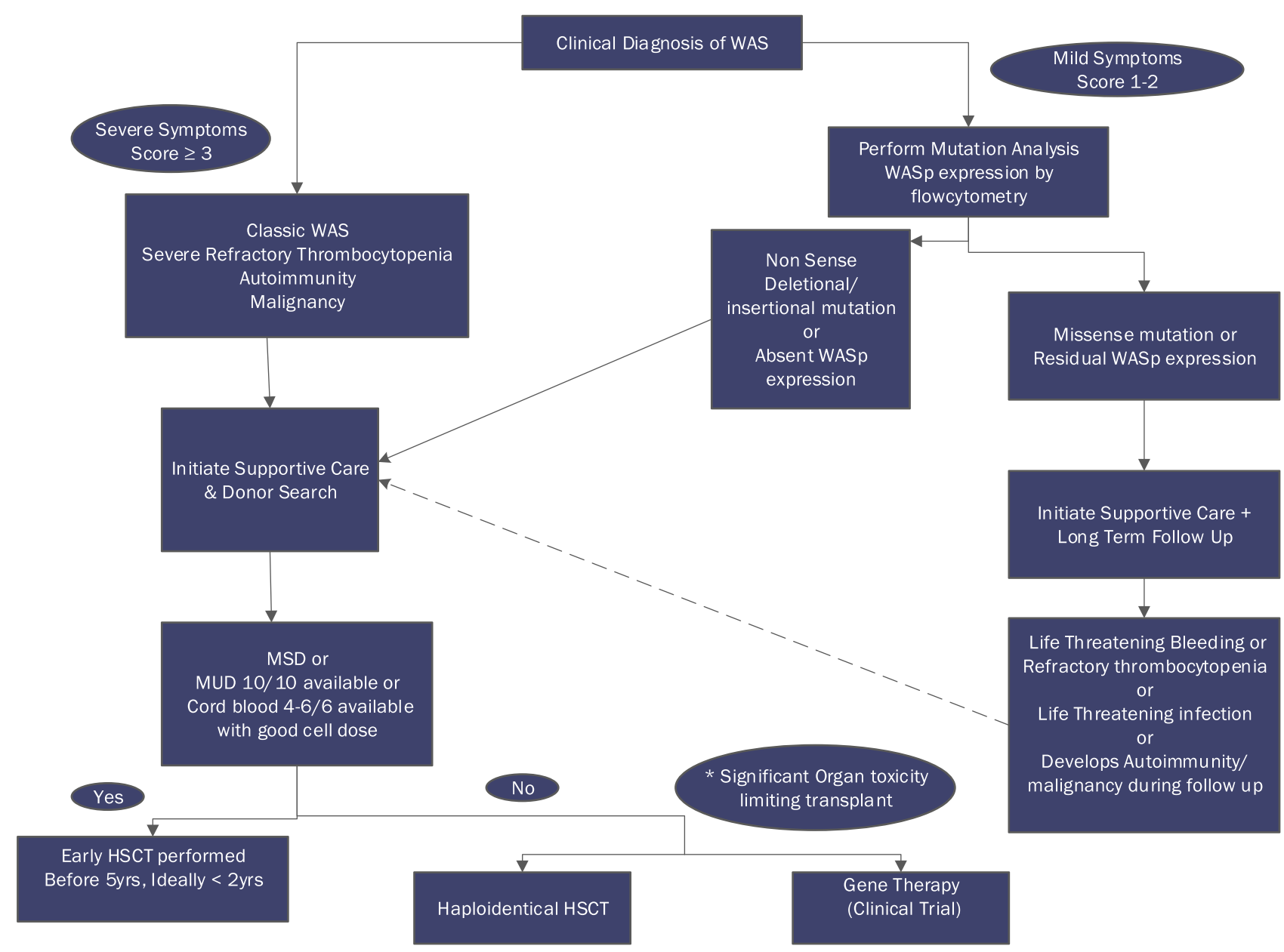

Figure I Treatment decision algorithm for WAS/ XLT based on the severity of clinical symptoms, type of genetic mutation, and WASp expression. For patients with classic WAS with a suitable MSD/MUD donor or CB 5-6/6 or 4/6 with a good cell dose, an early transplant should be performed. In the absence of a suitable matched donor, a Haploidentical transplant or gene therapy trial should be discussed. XLT patients with severe thrombocytopenia or mutation suggestive of a severe phenotype and absent WASp expression should also be transplanted. 
Table I Supportive Care in WAS

\begin{tabular}{|c|c|}
\hline \multicolumn{2}{|c|}{ Thrombocytopenia } \\
\hline General measures & Avoid contact sports, NSAIDs, and aspirin \\
\hline \multirow[t]{2}{*}{ Major bleeding } & Platelet transfusions \\
\hline & $\begin{array}{l}\text { Indicated only for active clinical bleeding/pre-procedural } \\
\text { Use only irradiated, CMV-negative, and leuco-reduced products } \\
\text { Minimize prophylactic platelet transfusions due to the risk of alloimmunization }\end{array}$ \\
\hline $\begin{array}{l}\text { Minor bleeding } \\
\text { Mucocutaneous bleeding }\end{array}$ & $\begin{array}{l}\text { Antifibrinolytic agents } \\
\text { Aminocaproic acid: } 100 \mathrm{mg} / \mathrm{kg} \text { loading dose, followed by } 50-100 \mathrm{mg} / \mathrm{kg} \text { every } 6 \\
\text { hrs } \times 7-10 \text { days }\end{array}$ \\
\hline Menorrhagia & Tranexamic acid $1300 \mathrm{mg}$ every $8 \mathrm{hrs}$ for 5 days at the start of menstruation \\
\hline $\begin{array}{l}\text { ITP } \\
\text { Suspect when no appropriate increment in platelets or resolution of } \\
\text { clinical bleeding after platelet transfusion }\end{array}$ & $\begin{array}{l}\text { IVIG I mg/kg single dose or steroids (first line) } \\
\text { Rituximab } 375 \mathrm{mg} / \mathrm{m}^{2} \text { weekly for } 4 \text { weeks (second line) }\end{array}$ \\
\hline Refractory thrombocytopenia & $\begin{array}{l}\text { Splenectomy } \\
\text { Normalizes platelet count and mean platelet volume, but associated high risk of } \\
\text { post-splenectomy sepsis especially post-transplant }\end{array}$ \\
\hline Other Investigational agents for thrombocytopenia & Eltrombopag and IL-2 being studied in clinical trials \\
\hline \multicolumn{2}{|c|}{ Recurrent Infections } \\
\hline Immunoglobulin replacement & $\begin{array}{l}400-600 \mu g / k g \text { should be started for all classical WAS and XLT with infections } \\
\text { IV every } 3 \text { weekly or SQ weekly } \\
\text { Higher doses of IgG replacements needed in WAS compared to other IEls due to } \\
\text { higher catabolism }\end{array}$ \\
\hline \multicolumn{2}{|l|}{ Prophylactic antimicrobials } \\
\hline Antibacterial and PJP prophylaxis & $\begin{array}{l}\text { Trimethoprim/Sulfamethoxazole } \\
30 \mathrm{mg} / \mathrm{kg} \text { once daily (based on trimethoprim component) }\end{array}$ \\
\hline Recurrent respiratory tract infections/ Pneumonia & $\begin{array}{l}\text { Azithromycin (For immunomodulatory action) } \\
10 \mathrm{mg} / \mathrm{kg} \text { PO } \times 3 \text { days/week }\end{array}$ \\
\hline Antiviral and antifungal & $\begin{array}{l}\text { Routine prophylaxis not indicated } \\
\text { Acyclovir considered in case of recurrent herpes simplex virus infections } \\
\text { Antifungals are considered for patients with a history of fungal infections }\end{array}$ \\
\hline Vaccines & $\begin{array}{l}\text { All live viral vaccines are contraindicated due to risk of infection from the vaccine } \\
\text { strain } \\
\text { Do not administer any vaccines other than flu vaccine once immunoglobulin } \\
\text { replacement is started }\end{array}$ \\
\hline \multicolumn{2}{|r|}{ Eczema } \\
\hline General measures & $\begin{array}{l}\text { Skin hydration using emollients and moisturizers is the key } \\
\text { Dietary modification including hypoallergenic formula }\end{array}$ \\
\hline Topical steroids & $\begin{array}{l}\text { Use thick creams/ointments with low/no water content } \\
\text { Desonide } 0.05 \% \text {, hydrocortisone } 2.5 \% \text { (low potency) } \\
\text { Fluocinolone } 0.025 \% \text {, triamcinolone } 0.1 \% \text {, betamethasone dipropionate } 0.05 \% \\
\text { (medium to high potency) }\end{array}$ \\
\hline Severe recalcitrant eczema & Dermatology consultation, wet wraps, dupilumab (IL-4 receptor alpha antagonist) \\
\hline Pruritus associated with eczema & Oral antihistamines \\
\hline
\end{tabular}


have also found no reduction in the risk of autoimmune and lymphoproliferative disorders after HSCT in splenectomized patients. ${ }^{50,51}$ Lifelong antibiotic prophylaxis is recommended for WAS/XLT patients who undergo splenectomy. As a result, the current trend is to avoid splenectomy, especially in patients who will undergo transplants.

\section{Low-Dose Interleukin-2 (IL-2)}

Low-dose IL-2 was employed as an immunostimulant treatment in WAS/XLT patients in Phase 1 clinical research at a level of 0.5 million $\mathrm{U} / \mathrm{m}^{2} /$ day. There was a statistically significant rise in platelet count, as well as high $\mathrm{T}, \mathrm{B}$, and NK cell numbers and $T$ regulatory cell percentages. More research is needed, however, to prove efficacy. ${ }^{52}$

\section{Thrombopoietin Mimetics}

Eltrombopag has been explored in patients with hereditary thrombocytopenia, including WAS/XLT, and has shown a slight rise in platelet count. Zaninetti et al in their Phase II clinical trial enrolling patients with various inherited thrombocytopenia including WAS/XLT, treated patients with a 3- to 6-week course of eltrombopag. The pretreatment platelet count of the cohort was $40,000 / \mu \mathrm{L}$ and post-treatment, 11 out of 23 patients $(47.8 \%)$ showed a major response (platelet count $>100,000 / \mu \mathrm{L}$ ) and 10 $(43.5 \%)$ showed a minor response (platelet count at least twice the baseline value) and $2(8.7 \%)$ had no response. Eltrombopag was well tolerated without any major side effects. $^{53}$

Eltrombopag was used as a bridge to transplant in a patient with early-onset WAS with severe refractory thrombocytopenia with a high frequency of clinical bleeding. The initial starting dose of eltrombopag used was $0.8 \mathrm{mg} / \mathrm{kg} / \mathrm{day}$ and increased up to a maximum of $5 \mathrm{mg} /$ $\mathrm{kg} /$ day. The patient benefitted with a significant reduction in clinical bleeding symptoms with complete elimination of platelet transfusion reducing the risk of alloimmunization. ${ }^{54}$

Gerrits et al investigated the effect of eltrombopag on platelet count and platelet activation in WAS/XLT patients in a clinical trial enrolling nine WAS/XLT patients and eight age-matched controls. In this study, eltrombopag had favorable effects on increasing platelet count but not platelet activation in WAS/XLT, the reason being micro platelets. Platelet function as measured by agonist-induced surface GPIIb-IIIa and P-selectin activation was proportional to the platelet size in WAS/XLT patients. ${ }^{55}$

\section{Autoimmunity and Malignancy}

AIHA is treated with corticosteroids. Other immunosuppressive medications, such as IVIG, rituximab, cyclophosphamide, azathioprine, and calcineurin inhibitors, have been utilized to treat autoimmune diseases linked to WAS. The use of immunosuppressive drugs to treat autoimmunity could potentially increase the risk of infection in WAS patients. In several trials, definitive therapy with HSCT resulted in the resolution of autoimmunity. ${ }^{4}$ Treatment for various cancers is similar to that of other pediatric oncology patients.

\section{Definitive Therapy Hematopoietic Stem Cell Transplantation in WAS}

The first successful transplant for WAS was performed in 1968 on a 2 -year-old boy. ${ }^{56}$ Since then, allogeneic HSCT has emerged as the most reliable curative treatment for WAS as it can correct both hematologic and immunologic abnormalities. Early referral to transplant and suitable donor search should be initiated immediately following diagnosis. HLA typing of the patient and all potential family members should be implemented. In the absence of a suitable family donor, matched unrelated donor search through a worldwide registry should be initiated. Various published studies on transplants along with salient features are illustrated in Table 2.

\section{Indications for Transplant}

The decision to transplant is usually made based on the clinical severity, the type of genetic mutation, and residual WASp expression. HSCT is recommended for all patients with classic/severe WAS (Clinical score $\geq 3$ ) and those with severe refractory thrombocytopenia due to the risk of life-threatening bleeding. Autoimmunity or malignancy (clinical score 5) are two other high-risk conditions that require transplantation. In young children in whom disease manifestation is yet incomplete, the presence of severe genetic mutation and/or absence of WASp expression should guide towards transplant, as the natural course of the disease is expected to worsen over time. Imai et al in their study demonstrated a correlation of WASp expression to survival, where WASp - $(\mathrm{n}=23)$ patients had a lower 10year overall survival $(\mathrm{OS})$ than WASp $+(\mathrm{n}=27)$ individuals $(76 \%$ vs $92.3 \%){ }^{12}$

Unlike classic WAS, clear recommendations on the role and timing of HSCT in XLT are lacking. Albert et al 


\begin{tabular}{|c|c|c|c|c|c|c|c|}
\hline 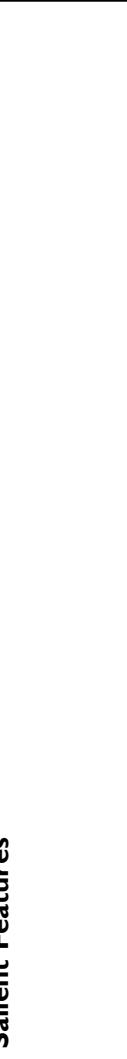 & 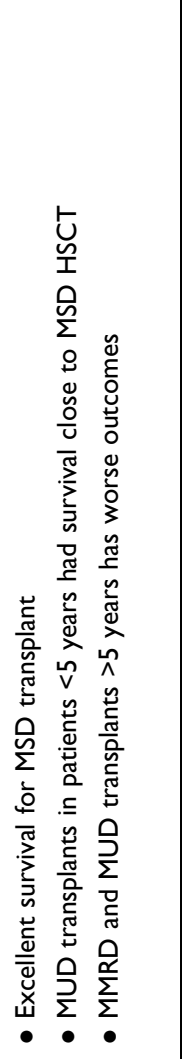 & 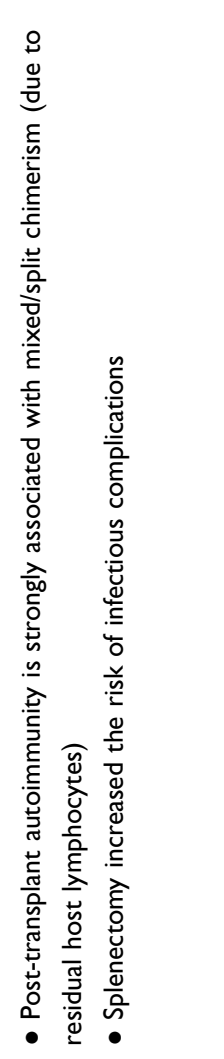 & 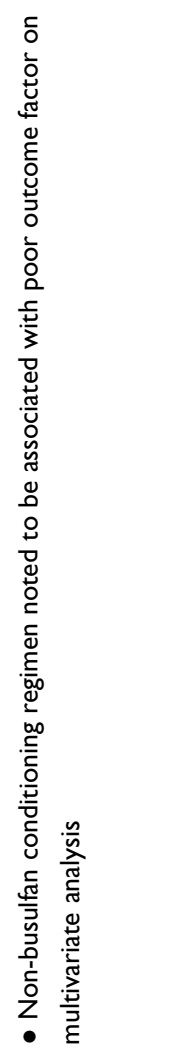 & 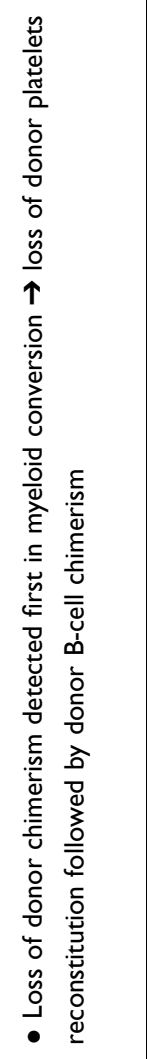 & 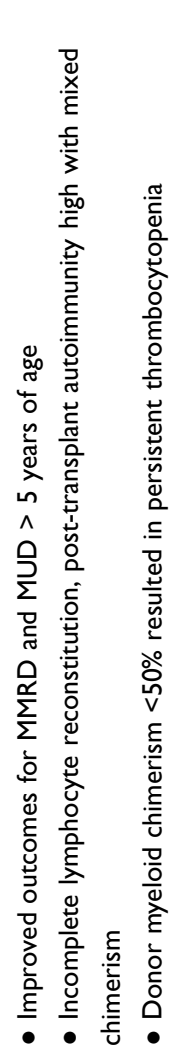 & 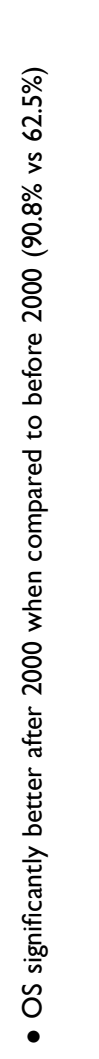 & 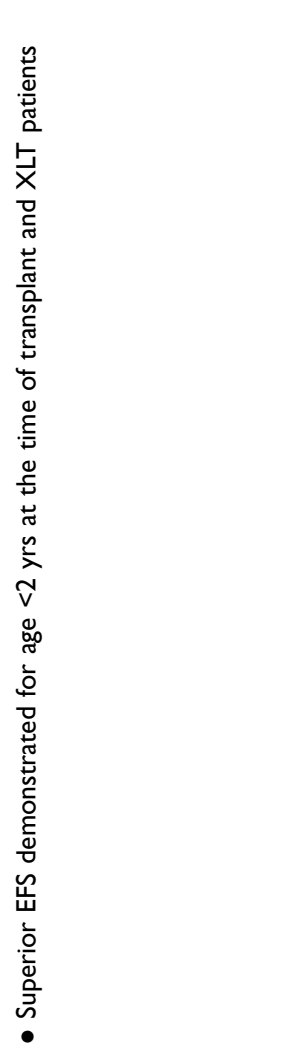 \\
\hline 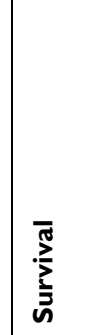 & 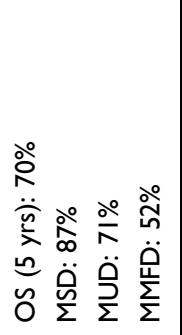 & 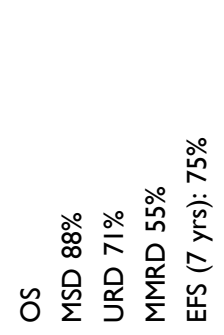 & 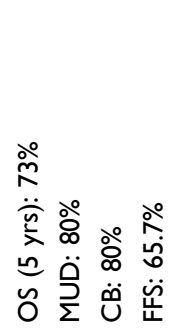 & 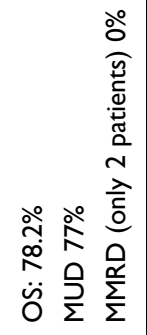 & 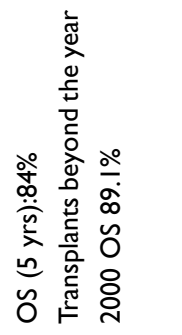 & 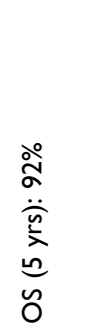 & 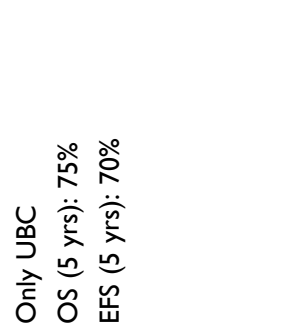 \\
\hline 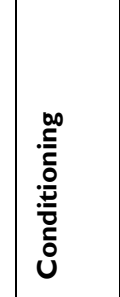 & $\begin{array}{l}\overline{\underline{m}} \\
\hat{\imath} \\
\bar{o}\end{array}$ & $\begin{array}{l}\widehat{U} \\
\bar{\emptyset}\end{array}$ & 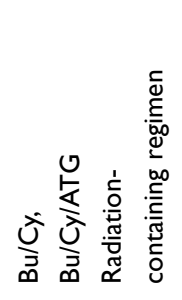 & 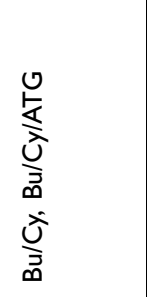 & 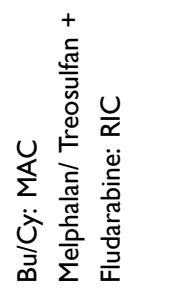 & 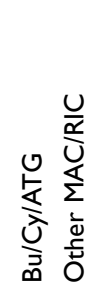 & 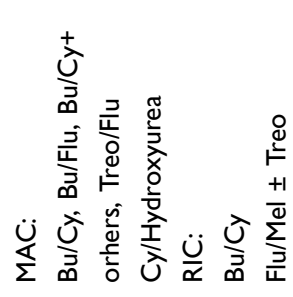 \\
\hline 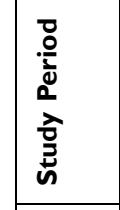 & 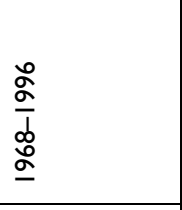 & 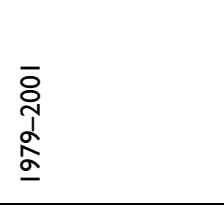 & 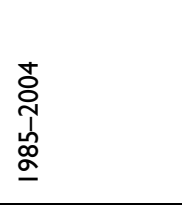 & 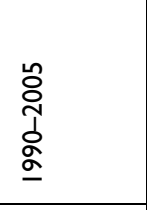 & 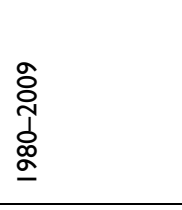 & 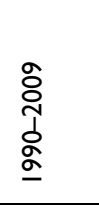 & $\begin{array}{l}\frac{m}{\circ} \\
\vdots \\
\vdots \\
\sigma\end{array}$ \\
\hline 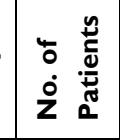 & $\underline{\text { P }}$ & ஃ & in & $\ddot{\sim}$ & $\stackrel{\Xi}{\stackrel{\Xi}{\sigma}}$ & $\hat{f}$ & ㅇ \\
\hline & 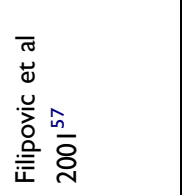 & 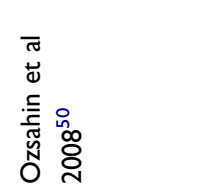 & 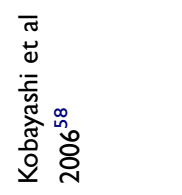 & 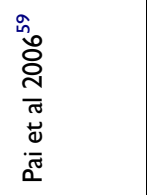 & 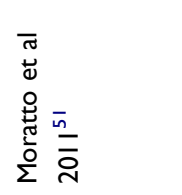 & 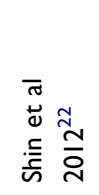 & 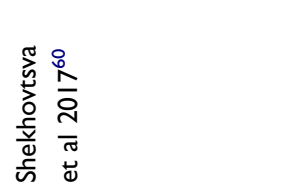 \\
\hline
\end{tabular}




\begin{tabular}{|c|c|c|}
\hline 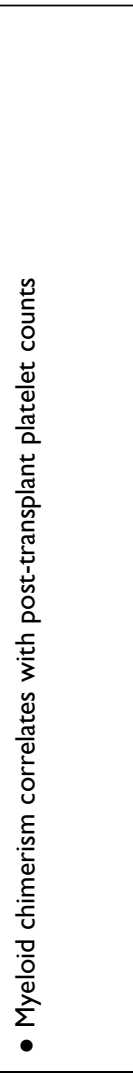 & 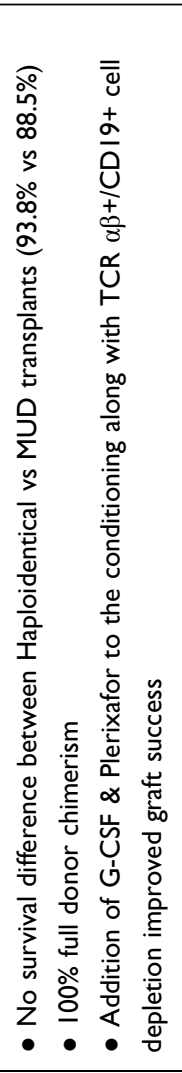 & 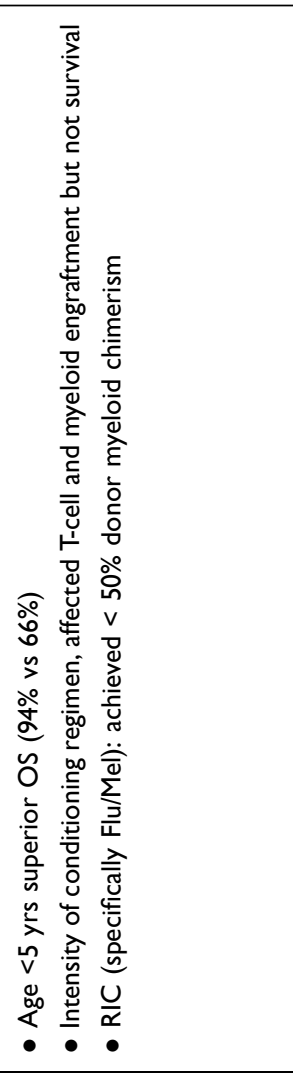 \\
\hline $\begin{array}{l}\stackrel{\circ}{\circ} \\
\text { ஸे } \\
\text { Oे }\end{array}$ & $\begin{array}{l}\frac{\circ}{\alpha} \\
\ddot{ஸ े ~}\end{array}$ & 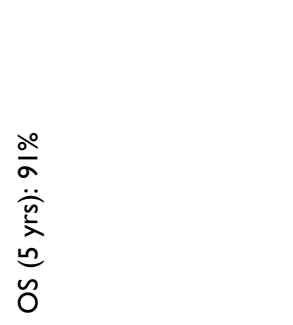 \\
\hline 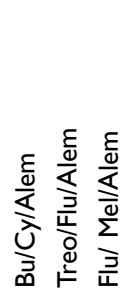 & 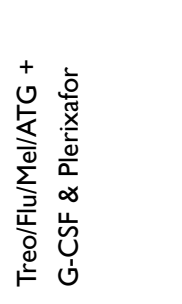 & 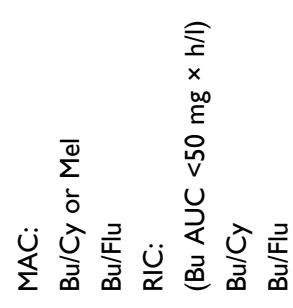 \\
\hline 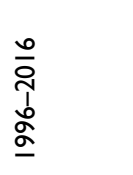 & $\begin{array}{l}\text { ̄ } \\
\text { İ } \\
\text { ড̀ }\end{array}$ & 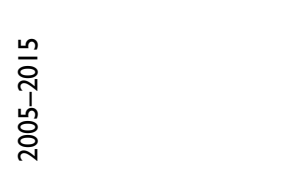 \\
\hline$\stackrel{+}{m}$ & ల & సิ \\
\hline 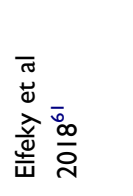 & 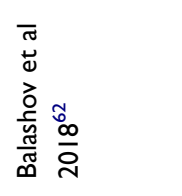 & 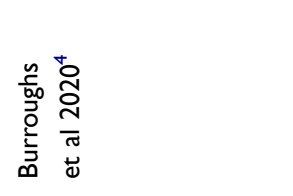 \\
\hline
\end{tabular}

found that, despite good OS rates, event-free survival (EFS) was unsatisfactory in a long-term outcome study of XLT patients. XLT individuals suffered major bleeding (13.9\%), life-threatening infections (6.9\%), autoimmunity (12.1\%), and cancer (5.2\%) during follow-up, according to the same study. ${ }^{63}$ As a result, if MSD is available, HSCT should be considered for XLT patients.

\section{Timing of Transplant}

Multiple studies have consistently found that transplants performed at a younger age (under 5 years) had superior OS rates. ${ }^{51,64}$ Burroughs et al found that in their cohort of 129 patients, the 5 -year OS rate was $94 \%$ vs $66 \%$ with $\mathrm{P}=0.0008$ for patients transplanted $<5$ years vs $>5$ years, respectively. ${ }^{4}$ Also, they reported intensity of conditioning regimen, donor type, hematopoietic stem cell source, HSCT year, WAS score, and WASp expression were not significantly associated with $\mathrm{OS}^{4}$ On the contrary, Moratto et al described transplants performed after the year 2000 as having improved survival for all donor types. ${ }^{51}$ Transplant at an older age may be complicated by the risk of primary disease progression with development of autoimmunity or cancer, viral reactivation, and a higher prevalence of graft versus host disease (GVHD). ${ }^{64-66}$ Whereas, transplant in infants should be proceeded with caution due to the potential disadvantage of toxicity of the conditioning regimen and variation in drug metabolism at such a young age.

\section{Donor Type and Graft Source}

A matched sibling donor (MSD) is the preferred donor for HSCT with excellent 5-year Overall Survival (OS) 90$95 \%$ and event-free survival (EFS) of $88 \% .^{22,50,64}$ Historically, inferior outcomes were reported in the setting of matched unrelated donors (MUD) and mismatched related donors (MMRD) when compared to MSD. Filipovich et al in a cohort of 170 patients, studied between 1968 and 1996 in a collaborative study of International Bone Marrow Transplant Registry (IBMTR) and National Marrow Donor Program (NMDP) reported a 5 -year OS of $87 \%$ with MSD, $52 \%$ with other related donors and $71 \%$ with unrelated donors. This excellent outcome with unrelated donors was reported when age at transplant was $<5$ years; however, patients $>5$ years had a poor outcome ${ }^{57}$ Contrary to this study, recent literature shows improved transplant outcomes over time for all donor types. ${ }^{4,50}$ This is attributed to better donor selection and a wider worldwide donor base, use of less toxic 
conditioning regimen, effective GVHD management, and advances in prevention and treatment of infection. ${ }^{51}$

Alternative donor transplants including umbilical cord blood (UCB) and mismatched related/haploidentical transplants were demonstrated to have poor outcomes according to earlier studies. ${ }^{50,51}$ However, in the last decade, better cord selections and effective measures to overcome graft failure/rejection and GVHD have paved the way for successful use of alternative donors in WAS boys who lack suitable matched donors. ${ }^{4,50,51}$ In a Primary Immunodeficiency Disease Treatment Consortium (PIDTC) report conducted between 2005 and 2015, Burroughs et al reported use of CB grafts in 39 of 129 patients $(30 \%)$ and reported an excellent 5-year OS of $90 \%$. Shekhovtsva et al published results for UCB outcomes on 90 patients using myeloablative (MAC) conditioning and anti-thymocyte globulin and reported five-year OS rates of $75 \%$ and an EFS of $70 \%$. Improved outcomes with $\mathrm{CB}$ in this study have also been attributed to better cord selection, higher CD34 cell dose, and improved supportive care.

Before the year 2000, T cell-depleted haploidentical or mismatched unrelated grafts were reported to be associated with high transplant-related mortality (TRM) of $38-55 \%$, which was attributed to graft failure, GVHD, and infectious complications. ${ }^{46}$ Improved outcomes reported in the recent era are due to the use of or posttransplant cyclophosphamide (PT-Cy) or T cell depletion bearing $\alpha \beta$ receptor implicated in causing GVHD, and CD19-positive cells harboring EBV. ${ }^{62,67}$ Balashov et al reported a dramatic decrease in the incidence of GVHD and TRM in a haploidentical transplant with T cell receptor (TCR) $\alpha \beta+/$ CD19+ graft depletion with a reported OS of $88.9 \%$. However, mixed myeloid donor chimerism and secondary graft rejection (graft rejection and severe thrombocytopenia) were reported in 7 out of 18 patients in the current series. Hence, in patients undergoing MUD/Haplo transplant with TCR $\alpha \beta+/ C D 19+$ graft depletion, the same investigators proposed the addition of G-CSF $(10 \mu \mathrm{g} / \mathrm{kg} /$ day for 5 days starting on day -8$)$ and plerixafor $(240 \mu \mathrm{g} /$ $\mathrm{kg} /$ day for 3 days starting on day -6 ) to the conditioning regimen, in a clinical trial and demonstrated full donor chimerism with OS rates of $93.8 \%$ without any graft dysfunction. $^{62}$ Another recent study by Elfeky et al reported $100 \%$ OS in 34 patients including alternative donor transplants with a median follow-up of 63 months. ${ }^{61}$ Though very promising, limitations of TCR $\alpha \beta$ + depletion include high cost and restricted availability, making PT-Cy a realistic choice for GVHD prophylaxis in alternative donor transplant. ${ }^{68}$

Bone marrow (BM) as a graft source is preferred due to the high risk of chronic GVHD with peripheral blood stem cells. A fully matched graft (either BM or PBSC) is a 10/ 10 match at HLA-A, -B, -C, -DRB1, and -DQB1 at the antigen level for MSD and allele level for MUD. For cord blood, 6/6 is considered a full match at HLA-A and -B at the antigen level and -DRB1 at the allele level. ${ }^{4}$

\section{Conditioning Regimen}

The first patient who underwent HSCT for WAS received minimal conditioning and demonstrated donor-derived T-cell reconstitution but failed to achieve donor-derived myeloid reconstitution. However, a second transplant from the same donor following a myeloablative conditioning regimen resulted in successful platelet engraftment. These initial transplant experiences highlighted that WAS patients have a selective advantage for WASp expression in lymphoid lineage compared to platelets, resulting in early $\mathrm{T}$ cell reconstitution and no platelet reconstitution unless both myeloablative and immune-ablative conditioning regimen is used. Conventional myeloablative conditioning regimens used include Busulfan and Cyclophosphamide. To reduce the toxicity associated with the conditioning regimen, reduced-dose busulfan and treosulfan-based regimens are increasingly being used. One of the primary problems with WAS posttransplant is mixed donor chimerism, which was highest with the reduced-intensity conditioning (RIC) regimens. ${ }^{4,50,69}$ Furthermore, even with myeloablative conditioning (MAC) regimens, a substantial risk of mixed donor chimerism exists (19-30\%), especially with MMRD. The degree of mixed donor chimerism in the post-transplant setting is a significant factor affecting platelet reconstitution. Hence, many experts in the field still recommend the use of MAC regimens due to higher frequencies of achieving full donor chimerism and better T-cell engraftment. ${ }^{4,51,59}$

Since WAS patients exhibit robust $\mathrm{T}$ Cell function compared to SCID patients, most protocols now include serotherapy (anti-thymocyte globulin [(ATG)/alemtuzu$\mathrm{mab}]$ ) in their conditioning regimens. Elfeky et al used RIC based on reduced-dose busulfan or treosulfan along with serotherapy with alemtuzumab/rabbit ATG and showed $100 \%$ survival with a median follow-up of 63 months in their cohort of patients with most patients receiving alternative donors. ${ }^{61}$ Treosulfan/lower-dose 
busulfan (area under the curve $65 \mathrm{mg} / \mathrm{L} / \mathrm{h}$ ), fludarabine, and serotherapy are currently the most widely employed reduced toxicity regimen. ${ }^{70}$

Nonmyeloablative conditioning was used by Burroughs et al for patients in whom infection/organ dysfunction precluded the use of MAC. Although stable donor engraftment and low early mortality were observed among those patients, a higher rate of GVHD was noted. ${ }^{71}$

\section{Post-Transplant Complications}

Most transplant-related complications occur within the first year after transplant and include mixed chimerism, infectious risk, autoimmunity, and malignancy, GVHD, TRM, and late effects such as infertility, second malignancies, endocrine issues, and organ dysfunction.

\section{Mixed Chimerism}

Mixed donor chimerism is a particular problem in patients with WAS in the post-transplant period. The reported incidence of mixed donor chimerism in various studies has been $\sim 19-50 \%$. $^{50,51,69}$ Mixed donor chimerism results in poor platelet reconstitution, subnormal lymphocyte counts, and autoimmune illness. ${ }^{22,50,51}$ According to Moratto et al, donor chimerism in the T-cell, B-cell, and Myeloid compartment was classified into four groups: full ( $>95 \%$ donor cells), high $(>50$ $95 \%)$, low $(5-50 \%)$, and null $(<5 \%)$ chimerism. In their cohort, $72.1 \%$ of the patients achieved full donor chimerism in all three compartments, $27.9 \%$ mixed chimerism in at least one of the compartments, low or null donor chimerism was more common in myeloid cells $(16.5 \%)$ in comparison to $\mathrm{B}$ cells $(7.4 \%)$ and $\mathrm{T}$ cells $(3.2 \%)$. Although low donor chimera was seen in the first year after HSCT, improved donor chimerism with stabilization was reported in a significant proportion of patients over time. ${ }^{51}$ Platelet reconstitution after HSCT is linked to the degree of myeloid donor chimerism, with higher platelet counts achieved in full donor chimerism compared to low-level chimerism. ${ }^{4}$ Type of conditioning was the major determinant of mixed donor chimerism, with RIC linked to a higher likelihood than MAC.

Donor myeloid chimerism $<50 \%$ was associated with higher rates of platelet transfusion dependence and subsequent graft failure. ${ }^{51,72}$ One other mechanism for a low degree of donor myeloid chimerism is the emergence of autoimmune thrombocytopenia in the post-transplant period. ${ }^{72}$ In cases of incomplete reconstitution, close monitoring of the donor chimerism is critical, and therapies such as stem cell boost, donor lymphocyte infusion, or a second transplant may be required.

\section{Post-Transplant Autoimmunity}

The incidence of post-transplant autoimmunity usually occurs within 2 years after HSCT and has been reported to be $20 \%{ }^{50}$ Pre-transplant autoimmunity was not a risk factor for post-transplant autoimmunity. Although earlier studies reported mixed donor chimerism after MUD or MMRD HSCT as an independent risk factor to develop de novo post-transplant autoimmunity, subsequent studies failed to reproduce the same results. ${ }^{4,22,50,51,61}$ In a recent study, Burroughs et al reported an increased incidence of autoimmunity with mixed myeloid chimerism at 6 months post-transplant; however, this was not observed on longterm follow-up. Donor type is a significant consideration as post-transplant autoimmunity was seen in none of the MSD, unlike $23 \%$ of unrelated and $9 \% \mathrm{CB}$ grafts. ${ }^{4}$

Autoimmune cytopenias (hemolytic anemia, thrombocytopenia, and neutropenia) are the predominant manifestation of autoimmunity in the post-transplant period, with a reported incidence varying between $14 \%$ and $72 \%$. $^{12,50,69,73}$

\section{GVHD}

Sophisticated HLA matching technology, allograft manipulation in alternative donor transplants, and with appropriate GVHD prophylaxis, the incidence of acute GVHD has decreased in WAS transplanted patients. The cumulative incidence of day 100 chronic GVHD as reported by Burroughs et al was $17 \%$, and there was no difference in the incidence of acute/chronic GVHD based on the different graft types. $^{4}$

\section{Infections}

WAS transplanted patients are at risk for serious, as well as fatal, infections, even 2 years after transplant. Ozashin et al demonstrated that risk of severe infections correlated with splenectomy, and strongly advocated against splenectomy in patients who are transplant candidates/transplant recipients. ${ }^{50}$ Shin et al reported viral reactivation in $84 \%$ (26/31 patients) of transplant recipients using viral polymerase chain reaction (PCR) tests. Age at transplant was a significant predictor in their study, which demonstrated patients transplanted $<2$ years had $71 \%$ viral reactivation vs $100 \%$ in those transplanted $>2$ years. $^{22}$ Periodic surveillance with quantitative PCR, preventive measures and aggressive treatment of infections are crucial in the post-transplant period. 


\section{Post-Transplant Malignancy}

The true incidence of post-transplant malignancy is unknown due to limited published results. Kamani et al in their CIBMTR study on malignancies after HSCT in primary immunodeficiency disorders (PIDs) reported the highest incidence of malignancy of $3.3 \%$ ( $n=360$ patients) for WAS when compared to $2.3 \%$ for other PIDs. Various reported malignancies included lymphoproliferative disorders (LPD) [mainly, EBVrelated post-transplant lymphoproliferative disorder (PTLD)], Immunoblastic B-cell lymphoma and large-cell lymphoma, diffuse large B-cell lymphoma (DLBCL) high-grade NHL, myelodysplasia and AML. ${ }^{3,22,50,51,74}$ Significant risk for development of LPD was the use of T cell-depleted graft as demonstrated by the fact that the median time to LPD from HSCT was 3 months. $^{74,75}$

\section{Late Effects}

While the overall incidence of late effects after HSCT for WAS is lower than for SCID, Ozashin et al found a higher incidence $(20 \%)$ of late complications and irreparable damage with sequela of those who survived beyond 2 years with a 7-year EFS of 75\%. Long-term side effects from conditioning regimens, chronic GVHD, veno-occlusive disease, endocrine complications, and hampered growth and development are of main concern. Unique challenges of transplanting an immunodeficiency disorder include systemic distribution of some of these genetic defects and incomplete understanding of the natural history of these defects.

\section{Gene Therapy for WAS}

Gene therapy (GT) using viral vectors to treat WAS has the potential to become a promising alternative for patients without a suitably matched donor and/or patients with disease-related comorbidities that increase the risk for transplant-related mortality. The ex-vivo transduction of autologous hematopoietic stem cells with lentiviruses or retroviruses can be used to restore normal WASp to cells. $^{76}$

The first gene therapy clinical trial for WAS started in 2006 in Hanover, Germany. The trial used a Moloney Leukemia virus-derived $\gamma$-retroviral vector. Ten patients were treated with peripheral blood mononuclear cells after receiving GCSF \pm plerixafor. The conditioning regimen consisted of Busulfan $8 \mathrm{mg} / \mathrm{kg}$ followed by the infusion of $2.9 \times 10^{6}$ to $24.9 \times 10^{6} \mathrm{CD} 34+$ cells $/ \mathrm{kg}$. Although nine out of ten patients achieved immune reconstitution and correction of WASP expression with the improvement of clinical status and WAS scores, this trial had an unacceptably high risk of insertional mutagenesis, with activation of several proto-oncogenes leading to T-ALL in six patients (488-1813 days after GT) and one patient with AML 1165 days after GT. Blood analysis of these patients showed clusters of integration sites near LMO2, CCND2, MDS1/EVI1 genes. ${ }^{77,78}$

Subsequent clinical trials have used a self-inactivating lentiviral vector (SIN-LV) for WAS gene correction. Conditioning regimens for these trials included Busulfan $(12 \mathrm{mg} / \mathrm{kg})$, and Fludarabine $120 \mathrm{mg} / \mathrm{m}^{2}$. Target busulfan AUC differed between trials from 60 to 82 . The trial conducted in Milan used a lower dose of busulfan (6.4$9.6 \mathrm{mg} / \mathrm{kg}$ with a target AUC of 48 ), Fludarabine $60 \mathrm{mg} /$ $\mathrm{m} 2$, and anti-CD20 monoclonal antibody (mAb). To date, a total of 34 patients with WAS have been treated with LVtransduced autologous bone marrow or mobilized peripheral-derived CD34+ cells. Ninety-one percent of the patients survived and sustained multi-lineage engraftment of cells expressing the WASp with associated significant improvement of symptoms. ${ }^{79-81}$ Even in the European trial that included mostly patients with severe WAS (score 5 in 6 out 7 patients) gene therapy was well tolerated with evident clinical improvement. One patient died from multiagent-resistant septic shock 7 months after gene therapy. The surviving patients experienced resolution of severe eczema, recurrent infections, autoimmunity, and after 7 months, these patients did not require regular transfusions or the use of TPO mimetics. Immune reconstitution with normal absolute $\mathrm{T}$ cell counts was seen in four out of six patients. Despite showing an improvement in platelet size, platelet numbers remained below normal values for all patients, but no severe bleeding symptoms were reported. ${ }^{79}$ In contrast, two out of the five patients treated in Boston did not show resolution of autoimmunity after gene therapy. Gene therapy for WAS using SIN-LV has not been associated with severe adverse events, including no evidence of the transformation of hematopoietic cells as was observed with the previous retroviral vectors despite vector integration adjacent to proto-oncogenes. ${ }^{79,80,82}$

A recently published long-term analysis of seventeen patients treated with WASp SIN-LV OTL-103 at an Italian hospital reported that all surviving patients who achieved multilineage engraftment and sustained WASp expression in lymphocytes and platelets, sustained improvement in infection risk and bleeding events after 8 years posttreatment. ${ }^{80}$ Salient features of HSCT versus gene therapy are highlighted in Table 3. 
Table 3 HSCT Vs Gene Therapy

\begin{tabular}{|c|c|c|}
\hline $\begin{array}{l}\text { Previous } \\
\text { Experience }\end{array}$ & $\begin{array}{l}\text { "Proven Curative Therapy" ( } 50 \text { Years of } \\
\text { Experience) }\end{array}$ & Offered Only as "Clinical Trial” ( 10 Years of Experience) \\
\hline $\begin{array}{l}\text { Conditioning } \\
\text { regimen }\end{array}$ & $\begin{array}{l}\text { MAC: } \\
\text { MAC preferred over RIC } \\
\text { (Due to low risk of mixed donor chimerism) } \\
\text { Nonmyeloablative: Used only in patients in whom } \\
\text { MAC usage is restricted due to organ dysfunction }\end{array}$ & $\begin{array}{l}\text { RIC: } \\
\text { Busulfan + Fludarabine }\end{array}$ \\
\hline Viral vector & $\mathrm{N} / \mathrm{A}$ & $\begin{array}{l}\text { Retroviral vector showed good engraftment and WAS protein } \\
\text { reconstitution but high risk for leukemogenesis (7/I0 patients). } \\
\text { wI.6W LV vector used in } 34 \text { patients (no clonal selection reported } \\
\text { with some patients with almost a decade of follow-up) }\end{array}$ \\
\hline $\begin{array}{l}\text { Correction of } \\
\text { underlying } \\
\text { abnormalities }\end{array}$ & $\begin{array}{l}\text { Corrects all abnormalities provided full donor } \\
\text { chimerism results } \\
\text { Correction of thrombocytopenia needs at least } \\
>50 \% \text { myeloid donor chimerism. }\end{array}$ & $\begin{array}{l}\text { Substantial improvement of all listed abnormalities without full } \\
\text { expression of WASp in all hematopoietic cell lines. } \\
\text { Thrombocytopenia increased from pretreatment values with an } \\
\text { improvement of MPV, improved frequency and severity of bleeding } \\
\text { episodes. }\end{array}$ \\
\hline WASp expression & Selective advantage for T cells $\gg B$ cells $\gg$ Myeloid cells & Variable levels of reconstitution (lymphocyte selective advantage) \\
\hline Complications & $\begin{array}{l}\text { Acute and long-term toxicity from the conditioning } \\
\text { regimen like } \\
\text { Acute and chronic GVHD } \\
\text { Mixed donor chimerism } \\
\text { Post-transplant autoimmunity } \\
\text { Malignancy post HSCT }\end{array}$ & $\begin{array}{l}\text { No severe side effects related to gene therapy were reported with } \\
\text { lentivirus (LV). } \\
\text { However, the risk of insertional oncogenesis/clonal expansion exists. } \\
\text { None reported so far. } \\
\text { The longest follow-up is } 8.8 \text { years, still long-term data are needed. }\end{array}$ \\
\hline Age & $<5$ years and preferably $<2$ years good outcomes & $\begin{array}{l}\text { Can be performed even in older patients/adults who are considered } \\
\text { high risk for HSCT. }\end{array}$ \\
\hline Ongoing research & & $\begin{array}{l}\text { A cryopreserved product is being used to increase safety } \\
\text { (Currently being tested in a clinical trial: NCT03837483) }\end{array}$ \\
\hline Future scope & & $\begin{array}{l}\text { Improvement in vector construct to increase transgene expression } \\
\text { Evaluate the use of cryopreserved formulation of wl.6W-transduced } \\
\text { autologous CD34+ HSPC. } \\
\text { Refinement of conditioning regimen to increase gene-corrected } \\
\text { myeloid engraftment }{ }^{80}\end{array}$ \\
\hline
\end{tabular}

In summary, outcomes for WAS have significantly improved over the years with HSCT. Even with 90$100 \%$ survival reported in multiple studies, acute and long-term toxicity associated with transplant remains a concern. ${ }^{3,61}$ Gene therapy has demonstrated a better safety profile and can improve all features of WAS, despite limited long-term follow-up data. However, with the widespread availability and long-term safety data, gene therapy has the potential to become a standard therapeutic option.

\section{Acknowledgments}

Mandy Neudecker, Pediatric Librarian at Rainbow Babies and Children's Hospital.

\section{Disclosure}

The authors report no conflicts of interest in this work.

\section{References}

1. Sullivan KE, Mullen CA, Blaese RM, Winkelstein JA. A multiinstitutional survey of the Wiskott-Aldrich syndrome. J Pediatr. 1994;125(6):876-885. doi:10.1016/S0022-3476(05)82002-5

2. Massaad MJ, Ramesh N, Geha RS. Wiskott-Aldrich syndrome: a comprehensive review. Ann N Y Acad Sci. 2013;1285(1):26-43. doi:10.1111/nyas.12049

3. Buchbinder D, Nugent DJ, Fillipovich AH. Wiskott-Aldrich syndrome: diagnosis, current management, and emerging treatments. Appl Clin Genet. 2014;7:55-66. doi:10.2147/TACG.S58444

4. Burroughs LM, Petrovic A, Brazauskas R, et al. Excellent outcomes following hematopoietic cell transplantation for Wiskott-Aldrich syndrome: a PIDTC report. Blood. 2020;135(23):2094-2105. doi:10.1182/ blood.2019002939 
5. Jin Y, Mazza C, Christie JR, et al. Mutations of the Wiskott-Aldrich Syndrome Protein (WASP): hotspots, effect on transcription, and translation and phenotype/genotype correlation. Blood. 2004;104 (13):4010-4019. doi:10.1182/BLOOD-2003-05-1592

6. Dupré L, Aiuti A, Trifari S, et al. Wiskott-Aldrich syndrome protein regulates lipid raft dynamics during immunological synapse formation. Immunity. 2002;17(2):157-166. doi:10.1016/S1074-761 3(02)00360-6

7. Blundell MP, Worth A, Bouma G, Thrasher AJ. The Wiskott-Aldrich syndrome: the actin cytoskeleton and immune cell function. Dis Markers. 2010;29(3-4):157-175. doi:10.3233/DMA-2010-0735

8. Moratto D, Giliani S, Notarangelo LD, Mazza C, Mazzolari E, Notarangelo LD. The Wiskott-Aldrich syndrome: from genotype-phenotype correlation to treatment. Expert Rev Clin Immunol. 2007;3(5):813-824. doi:10.1586/1744666X.3.5.813

9. Ochs HD, Thrasher AJ. The Wiskott-Aldrich syndrome. J Allergy Clin Immunol. 2006;117(4):725-738. doi:10.1016/j.jaci.2006.02.005

10. Symons M, Derry JMJ, Karlak B, et al. Wiskott-Aldrich syndrome protein, a novel effector for the GTPase CDC42Hs, is implicated in actin polymerization. Cell. 1996;84(5):723-734. doi:10.1016/S00928674(00)81050-8

11. Stewart DM, Tian L, Nelson DL. Mutations that cause the Wiskott-Aldrich syndrome impair the interaction of Wiskott-Aldrich syndrome protein (WASP) with WASP interacting protein. J Immunol. 1999;162(8):5019-5024.

12. Imai K, Morio T, Zhu Y, et al. Clinical course of patients with WASP gene mutations. Blood. 2004;103(2):456-464. doi:10.1182/blood2003-05-1480

13. Ochs HD. The Wiskott-Aldrich syndrome. IMA. 2002;4:379-384.

14. Bosticardo M, Marangoni F, Aiuti A, Villa A, Roncarolo MG. Recent advances in understanding the pathophysiology of Wiskott-Aldrich syndrome. Blood. 2009;113(25):6288-6295. doi:10.1182/blood2008-12-115253

15. Patel PD, Samanich J, William Mitchell DM, Manwani D. A unique presentation of Wiskott-Aldrich syndrome in relation to platelet size. Pediatr Blood Cancer. 2011;56(7):1127-1129. doi:10.1002/pbc.22 920

16. Skoric D, Dimitrijevic A, Cuturilo G, Ivanovski P. Wiskott-Aldrich syndrome with macrothrombocytopenia. Indian Pediatr. 2014;51 (12):1015-1016. doi:10.1007/s13312-014-0550-5

17. Mazumdar J, Kanjilal S, Das A. Wiskott-Aldrich syndrome with normal-sized platelets in an eighteen-month-old boy: a rare mutation. J Pediatr Rev. 2015;3(2):10-13. doi:10.17795/jpr-417

18. Bader-Meunier B, Proulle V, Trichet C, et al. Misdiagnosis of chronic thrombocytopenia in childhood. J Pediatr Hematol Oncol. 2003;25 (7):548-552. doi:10.1097/00043426-200307000-00010

19. Suri D, Rikhi R, Jindal AK, et al. Wiskott Aldrich Syndrome: A Multi-Institutional Experience From India. Front Immunol. 2021;12:627651. doi:10.3389/fimmu.2021.627651

20. Borte S, Fasth A, von Döbeln U, Winiarski J, Hammarström L. Newborn screening for severe $\mathrm{T}$ and $\mathrm{B}$ cell lymphopenia identifies a fraction of patients with Wiskott-Aldrich syndrome. Clin Immunol. 2014;155(1):74-78. doi:10.1016/J.CLIM.2014.09.003

21. Trifari S, Sitia G, Aiuti A, et al. Defective Th1 cytokine gene transcription in CD4 + and CD8 + T cells from Wiskott-Aldrich syndrome patients. $J$ Immunol. 2006;177(10):7451-7461. doi:10.40 49/jimmunol.177.10.7451

22. Shin CR, Kim MO, Li D, et al. Outcomes following hematopoietic cell transplantation for WiskottAldrich syndrome. Bone Marrow Transplant. 2012;47(11):1428-1435. doi:10.1038/bmt.2012.31

23. Chen N, Zhang ZY, Liu DW, Liu W, Tang XM, Zhao XD. The clinical features of autoimmunity in 53 patients with WiskottAldrich syndrome in China: a single-center study. Eur $J$ Pediatr. 2015;174(10):1311-1318. doi:10.1007/s00431-015-2527-3
24. Dupuis-Girod S, Medioni J, Haddad E. Autoimmunity in Wiskott-Aldrich syndrome: risk factors, clinical features and outcome in a single center cohort of 55 patients. Pediatrics. 2003;111(5): e622-e627. doi:10.1542/peds.111.5.e622

25. Lee PPW, Chen TX, Jiang LP, et al. Clinical and molecular characteristics of 35 Chinese children with Wiskott-Aldrich syndrome. J Clin Immunol. 2009;29(4):490-500. doi:10.1007/s10875-009-9285-9

26. Mars LT, Araujo L, Kerschen P, et al. Invariant NKT cells inhibit development of the Th17 lineage. Proc Natl Acad Sci. 2009;106 (15):6238-6243. doi:10.1073/pnas.0809317106

27. Perry GS, Spector BD, Schuman LM, et al. The Wiskott-Aldrich syndrome in the United States and Canada (1892-1979). J Pediatr. 1980;97(1):72-78. doi:10.1016/S0022-3476(80)80133-8

28. Keszei M, Snapper SB, Westerberg LS, et al. Constitutive activation of WASp in X-linked neutropenia renders neutrophils hyperactive graphical abstract find the latest version: constitutive activation of WASp in X-linked neutropenia renders neutrophils hyperactive. J Clin Invest. 2018;128(9):4115-4131. doi:10.1172/JCI64772

29. Cotelingam JD, Witebsky FG, Hsu SM, Blaese RM, Jaffe ES. Malignant lymphoma in patients with the Wiskott-Aldrich syndrome. Cancer Invest. 1985;3(6):515-522. doi:10.3109/07357908509039813

30. Yoshida K, Minegishi Y, Okawa H, et al. Epstein-Barr virus-associated malignant lymphoma with macroamylasemia and monoclonal gammopathy in a patient with Wiskott-Aldrich syndrome. Pediatr Hematol Oncol. 1997;14(October 1995):1-5.

31. Liu GH, Chen J, Ji ZG, Zhou L. Expression of neural Wiskott-Aldrich syndrome protein in clear cell renal cell carcinoma and its correlation with clinicopathological features. Urol Int. 2015;95(1):79-85. doi:10.1159/000365595

32. Huang L, Lian J, Chen X, Qin G, Zheng Y, Zhang Y. WASH overexpression enhances cancer stem cell properties and correlates with poor prognosis of esophageal carcinoma. Cancer Sci. 2017;108 (12):2358-2365. doi:10.1111/cas.13400

33. Martin TA, Pereira G, Watkins G, Mansel RE, Jiang WG. N-WASP is a putative tumour suppressor in breast cancer cells, in vitro and in vivo, and is associated with clinical outcome in patients with breast cancer. Clin Exp Metastasis. 2008;25(2):97-108. doi:10.1007/ s10585-007-9120-8

34. Jin KM, Lu M, Liu FF, Gu J, Du XJ, Xing BC. N-WASP is highly expressed in hepatocellular carcinoma and associated with poor prognosis. Surg (United States). 2013;153(4):518-525. doi:10.1016/ j.surg.2012.08.067

35. Bernabeu E, Josa M, Nomdedeu B, et al. One-step surgical approach of a thoracic aortic aneurysm in Wiskott-Aldrich syndrome. Ann Thorac Surg. 2007;83(4):1537-1538. doi:10.1016/j.athoracsur.2006.10.005

36. Wood G, Booth K, Khan Z, Biss T, Roysam C, Dark J. Descending aortic aneurysm in Wiskott-Aldrich syndrome: options for repair. Asian Cardiovasc Thorac Ann. 2017;25(9):635-637. doi:10.1177/ 0218492317738386

37. Pellier I, Girod SD, Loisel D, et al. Occurrence of aortic aneurysms in 5 cases of Wiskott-Aldrich syndrome. Pediatrics. 2011;127(2):e498e504. doi:10.1542/peds.2009-2987

38. Barutcu A, Goksel Leblebisatan SL, Metin Cil HI, Sasmaz FD, Sasmaz HI, Demir F. A case with Wiskott-Aldrich syndrome and ascending aorta aneurysm. J Pediatr Hematol Oncol. 2021;43: 774-776. doi:10.1097/MPH.0000000000001932

39. He T, Cao K, Qi Z, et al. Acquired hemophilia A in Wiskott-Aldrich syndrome. J Clin Immunol. 2021;41:1119-1122. doi:10.1007/s10875021-00978-9

40. Abhijit Anil Patil AD. Wiskott Aldrich syndrome having atypical presentation like Evans syndrome. Clin Pediatr (Phila). 2019;4:147.

41. Kumar A, Jain S, Kumar P, Goyal JP. Generalised eczema: a diagnostic clue to Wiskott-Aldrich syndrome. BMJ Case Rep. 2021;14:242642. doi:10.1136/bcr-2021-242642 
42. Albert MH, Notarangelo LD, Ochs HD. Clinical spectrum, pathophysiology and treatment of the Wiskott-Aldrich syndrome. Curr Opin Hematol. 2011;18(1):42-48. doi:10.1097/MOH.0b013e32834114bc

43. Thrasher AJ. WASp in immune-system organization and function. Nat Rev Immunol. 2002;2(9):635-646. doi:10.1038/nri884

44. Villa A, Notarangelo L, Macchi P, et al. X-linked thrombocytopenia and Wiskott-Aldrich syndrome are allelic diseases with mutations in the WASP gene. Nat Genet. 1995;9(4):414-417. doi:10.1038/ng0495414

45. Schindelhauer D, Weiss M, Hellebrand $\mathrm{H}$, et al. Wiskott-Aldrich syndrome: no strict genotype-phenotype correlations but clustering of missense mutations in the amino-terminal part of the WASP gene product. Hum Genet. 1996;98(1):68-76. doi:10.1007/s004390050162

46. Worth AJ, Thrasher AJ. Current and emerging treatment options for Wiskott-Aldrich syndrome. Expert Rev Clin Immunol. 2015;11 (9):1015-1032. doi:10.1586/1744666X.2015.1062366

47. Suri D, Singh S, Rawat A, et al. Clinical profile and genetic basis of Wiskott-Aldrich syndrome at Chandigarh, North India. Asian Pacific J Allerg Immunol. 2012;30(1):71-78.

48. Haskoloğlu Ş, Öztürk A, Öztürk G, et al. Clinical features and outcomes of 23 patients with Wiskott-Aldrich syndrome: a single-center experience. Turk J Hematol. 2020;37(4):271-281. doi:10.4274/tjh. galenos.2020.2020.0334

49. Mullen CA, Anderson KD, Blaese RM. Splenectomy and/or bone marrow transplantation in management of the Wiskott-Aldrich syndrome: long term follow-up of 62 cases. Blood. 1993;82 (10):2961-2966. doi:10.1182/blood.v82.10.2961.2961

50. Ozsahin H, Cavazzana-Calvo M, Notarangelo LD. Long-term outcome following hematopoietic stem-cell transplantation in Wiskott-Aldrich syndrome: collaborative study of the European Society for Immunodeficiencies and European Group for Blood and Marrow Transplantation. Blood. 2008;111(1):439-445. doi:10.1182/ blood-2007-03-076679

51. Moratto D, Giliani S, Bonfim C, et al. Long-term outcome and lineage-specific chimerism in 194 patients with Wiskott-Aldrich syndrome treated by hematopoietic cell transplantation in the period 1980-2009: an international collaborative study. Blood. 2011;118 (6):1675-1684. doi:10.1182/blood-2010-11-319376

52. Jyonouchi S, Gwafila B, Gwalani LA, et al. Phase I trial of low-dose interleukin 2 therapy in patients with Wiskott-Aldrich syndrome. Clin Immunol. 2017;179:47-53. doi:10.1016/J.CLIM.2017.02.001

53. Zaninetti C, Gresele P, Bertomoro A, et al. Eltrombopag for the treatment of inherited thrombocytopenias: a phase II clinical trial. Haematologica. 2020;105(3):820-828. doi:10.3324/haematol.2019.223966

54. Gabelli M, Marzollo A, Notarangelo LD, Basso G, Putti MC. Eltrombopag use in a patient with Wiskott-Aldrich syndrome. Pediatr Blood Cancer. 2017;64(12):1-3. doi:10.1002/pbc.26692

55. Gerrits AJ, Leven EA, Frelinger AL, et al. Effects of eltrombopag on platelet count and platelet activation in Wiskott-Aldrich syndrome/ X-linked thrombocytopenia. Blood. 2015;126(11):1367-1378. doi:10.1182/blood-2014-09-602573

56. Bach FH, Albertini RJ, Joo P, Anderson JL, Bortin MM. Bone-marrow transplantation in a patient with the Wiskott-Aldrich syndrome. Lancet. 1968;2(7583):1364-1366. doi:10.1016/s0140-6736(68)92672-x

57. Filipovich AH, Stone JV, Tomany SC, et al. Impact of donor type on outcome of bone marrow transplantation for Wiskott-Aldrich syndrome: collaborative study of the International Bone Marrow Transplant Registry and the National Marrow Donor Program. Blood. 2001;97(6):1598-1603. doi:10.1182/blood.V97.6.1598

58. Kobayashi R, Ariga T, Nonoyama S, et al. Outcome in patients with Wiskott-Aldrich syndrome following stem cell transplantation: an analysis of 57 patients in Japan. Br J Hematol. 2006;135:362-366. doi:10.1111/j.1365-2141.2006.06297.x
59. Pai SY, Notarangelo LD. Hematopoietic cell transplantation for Wiskott-Aldrich syndrome: advances in biology and future directions for treatment. Immunol Allergy Clin North Am. 2010;30(2):179-194. doi:10.1016/j.iac.2010.02.001

60. Shekhovtsova Z, Bonfim C, Ruggeri A, et al. A risk factor analysis of outcomes after unrelated cord blood transplantation for children with Wiskott-Aldrich syndrome. Haematologica. 2017;102(6):1112-1119. doi:10.3324/haematol.2016.158808

61. Elfeky RA, Furtado-Silva JM, Chiesa R, et al. One hundred percent survival after transplantation of 34 patients with Wiskott-Aldrich syndrome over 20 years. J Allergy Clin Immunol. 2018;142 (5):1654-1656.e7. doi:10.1016/j.jaci.2018.06.042

62. Balashov D, Laberko A, Shcherbina A, et al. A conditioning regimen with plerixafor is safe and improves the outcome of TCR $\alpha \beta+$ and CD19 + cell-depleted stem cell transplantation in patients with Wiskott-Aldrich syndrome. Biol Blood Marrow Transplant. 2018;24 (7):1432-1440. doi:10.1016/j.bbmt.2018.03.006

63. Albert MH, Bittner TC, Nonoyama S, et al. X-linked thrombocytopenia (XLT) due to WAS mutations: clinical characteristics, long-term outcome, and treatment options. Blood. 2010;115 (16):3231-3238. doi:10.1182/blood-2009-09-239087

64. Gennery AR, Slatter MA, Grandin L, et al. Transplantation of hematopoietic stem cells and long-term survival for primary immunodeficiencies in Europe: entering a new century, do we do better? J Allergy Clin Immunol. 2010;126(3):602-610.e11. doi:10.1016/j.jaci.2010.06.015

65. Gennery AR, Cant AJ. The immunocompromised host: the patient with recurrent infection. Adv Exp Med Biol. 2004;549:109-117. doi:10.1007/978-1-4419-8993-2_16

66. Seger RA, Gungor T, Belohradsky BH, et al. Treatment of chronic granulomatous disease with myeloablative conditioning and an unmodified hemopoietic allograft: a survey of the European experience, 1985-2000. Blood. 2002;100(13):4344-4350. doi:10.1182/ blood-2002-02-0583

67. Yue Y, Shi X, Song Z, et al. Posttransplant cyclophosphamide for haploidentical stem cell transplantation in children with WiskottAldrich syndrome. Pediatr Blood Cancer. 2018;65(8):1-5. doi: $10.1002 /$ pbc. 27092

68. Mallhi KK, Petrovic A, Ochs HD. Hematopoietic stem cell therapy for Wiskott- Aldrich syndrome: improved outcome and quality of life. J Blood Med. 2021;12:435-447. doi:10.2147/JBM.S232650

69. Yamaguchi K, Ariga T, Yamada M, et al. Mixed chimera status of 12 patients with Wiskott-Aldrich syndrome (WAS) after hematopoietic stem cell transplantation: evaluation by flow cytometric analysis of intracellular WAS protein expression. Blood. 2002;100(4):12 08-1214. doi:10.1182/blood-2002-01-0211

70. Slatter MA, Rao K, Abd Hamid IJ, et al. Treosulfan and fludarabine conditioning for hematopoietic stem cell transplantation in children with primary immunodeficiency: UK experience. Biol Blood Marrow Transplant. 2018;24(3):529-536. doi:10.1016/j.bbmt.2017.11.009

71. Burroughs LM, Storb R, Leisenring WM, et al. Intensive postgrafting immune suppression combined with nonmyeloablative conditioning for transplantation of HLA-identical hematopoietic cell grafts: results of a pilot study for treatment of primary immunodeficiency disorders. Bone Marrow Transplant. 2007;40(7):633-642. doi:10.1038/sj. bmt. 1705778

72. Ngwube A, Hanson IC, Orange J, et al. Outcomes after allogeneic transplant in patients with Wiskott-Aldrich syndrome. Biol Blood Marrow Transplant. 2018;24(3):537-541. doi:10.1016/j.bbmt.2017. 11.019

73. Stepensky P, Krauss A, Goldstein G, et al. Impact of conditioning on outcome of hematopoietic stem cell transplantation for Wiskott-Aldrich syndrome. J Pediatr Hematol Oncol. 2013;35 (6):234-238. doi:10.1097/MPH.0b013e318279cbfc 
74. Kamani NR, Kumar S, Hassebroek A, et al. Malignancies after hematopoietic cell transplantation for primary immune deficiencies: a report from the center for international blood and marrow transplant research. Biol Blood Marrow Transplant. 2011;17(12):1783-1789. doi:10.1016/j.bbmt.2011.05.008

75. Curtis RE, Travis LB, Rowlings PA, et al. Risk of lymphoproliferative disorders after bone marrow transplantation: a multi-institutional study. Blood. 1999;94(7):2208-2216. doi:10.1182/blood.V94.7.2208. 419k21 22082216

76. Bulaklak K, Gersbach CA. The once and future gene therapy. Nat Commun. 2020;11(1):11-14. doi:10.1038/s41467-020-19505-2

77. Braun CJ, Boztug K, Paruzynski A, et al. Gene therapy for Wiskott-Aldrich syndrome-long - term efficacy and genotoxicity (Science Translational Medicine). Sci Transl Med. 2014;6 (254):1-15. doi:10.1126/scitranslmed.3010603

78. Boztug K, Schmidt M, Schwarzer A, et al. Stem-cell gene therapy for the Wiskott-Aldrich syndrome. $N$ Engl J Med. 2010;363(20):19 18-1927. doi:10.1056/nejmoa1003548
79. Hacein-Bey Abina S, Gaspar HB, Blondeau J, et al. Outcomes following gene therapy in patients with severe Wiskott-Aldrich syndrome. JAMA. 2015;313(15):1550-1563. doi:10.1001/jama.2015. 3253

80. Ferrua F, Cicalese MP, Galimberti S, et al. Lentiviral haemopoietic stem/progenitor cell gene therapy for treatment of Wiskott-Aldrich syndrome: interim results of a non-randomised, open-label, phase $1 / 2$ clinical study. Lancet Haematol. 2019;6(5):e239-e253. doi:10.1016/ S2352-3026(19)30021-3

81. Morris EC, Fox T, Chakraverty R, et al. Gene therapy for Wiskott-Aldrich syndrome in a severely affected adult. Blood. 2017;130(11):1327-1335. doi:10.1182/blood-2017-04-777136

82. Sereni L, Castiello MC, Di Silvestre D, et al. Lentiviral gene therapy corrects platelet phenotype and function in patients with Wiskott-Aldrich syndrome. J Allergy Clin Immunol. 2019;144 (3):825-838. doi:10.1016/j.jaci.2019.03.012

\section{Publish your work in this journal}

The Journal of Multidisciplinary Healthcare is an international, peerreviewed open-access journal that aims to represent and publish research in healthcare areas delivered by practitioners of different disciplines. This includes studies and reviews conducted by multidisciplinary teams as well as research which evaluates the results or conduct of such teams or healthcare processes in general. The journal covers a very wide range of areas and welcomes submissions from practitioners at all levels, from all over the world. The manuscript management system is completely online and includes a very quick and fair peer-review system. Visit http://www.dovepress.com/testimonials. php to read real quotes from published authors. 